\title{
The impact of care environment on the mental health of orphaned, separated and street-connected children and adolescents in western Kenya: a prospective cohort analysis
}

\author{
Felicita Omari, ${ }^{1}$ Stavroula A Chrysanthopoulou, ${ }^{2}$ Lonnie E Embleton, ${ }^{3}$ \\ Lukoye Atwoli, ${ }^{4}$ David O Ayuku, ${ }^{5}$ Edwin Sang, ${ }^{6}$ Paula Braitstein (i) ${ }^{3}$
}

\begin{abstract}
To cite: Omari F,
Chrysanthopoulou SA,

Embleton LE, et al. The impact of care environment on the mental health of orphaned, separated and street-connected children and adolescents in western Kenya: a prospective cohort analysis. BMJ Global Health 2021;6:e003644. doi:10.1136/ bmjgh-2020-003644
\end{abstract}

Handling editor Soumitra S Bhuyan

- Additional material is published online only. To view, please visit the journal online (http://dx.doi.org/10.1136/ bmjgh-2020-003644).

Received 9 August 2020 Revised 9 February 2021 Accepted 4 March 2021

Check for updates

\section{(C) Author(s) (or their} employer(s)) 2021. Re-use permitted under CC BY-NC. No commercial re-use. See rights and permissions. Published by BMJ.

For numbered affiliations see end of article.

Correspondence to Dr Paula Braitstein; pbraitstein@gmail.com

\section{ABSTRACT}

Introduction The effect of care environment on orphaned and separated children and adolescents' (OSCA) mental health is not well characterised in sub-Saharan Africa. We compared the risk of incident post-traumatic stress disorder (PTSD), depression, anxiety and suicidality among OSCA living in Charitable Children's Institutions (CCls), family-based care (FBC) and street-connected children and youth (SCY).

Methods This prospective cohort followed up OSCA from 300 randomly selected households (FBC), $19 \mathrm{CCls}$ and 100 SCY in western Kenya from 2009 to 2019. Annual data were collected through standardised assessments. We fit survival regression models to investigate the association between care environment and mental health diagnoses.

Results The analysis included 1931 participants: 1069 in FBC, 783 in CCls and 79 SCY. At baseline, 1004 participants (52\%) were male with a mean age (SD) of 13 years (2.37); $54 \%$ were double orphans. In adjusted analysis (adjusted HR, AHR), OSCA in CCls were significantly less likely to be diagnosed with PTSD (AHR 0.69, 95\% Cl 0.49 to 0.97), depression (AHR $0.4895 \% \mathrm{Cl} 0.24$ to 0.97 ), anxiety (AHR $0.56,95 \% \mathrm{Cl}$ 0.45 to 0.68 ) and suicidality (AHR $0.73,95 \% \mathrm{Cl} 0.56$ to 0.95 ) compared with those in FBC. SCY were significantly more likely to be diagnosed with PTSD (AHR 4.52, 95\% Cl 4.10 to 4.97 ), depression (AHR 4.72, 95\% $\mathrm{Cl} 3.12$ to 7.15), anxiety (AHR 4.71, $95 \% \mathrm{Cl} 1.56$ to 14.26 ) and suicidality (AHR $3.10,95 \% \mathrm{Cl} 2.14$ to 4.48) compared with those in FBC.

Conclusion OSCA living in CCls in this setting were significantly less likely to have incident mental illness, while SCY were significantly more, compared with OSCA in FBC.

\section{INTRODUCTION}

Undergoing one or more potentially traumatic events (PTEs) in childhood, such as the loss of one or both parents, has been associated with mental health morbidities. ${ }^{12}$ Orphaned and separated (those semipermanently or permanently separated from their biological parents) children and adolescents (OSCA) in sub-Saharan Africa experience multiple PTEs ${ }^{2-4}$ and have substantial mental

\section{Key questions}

What is already known?

- Evidence, largely from higher-income settings such as Eastern Europe, has consistently demonstrated deficits and delays in physical growth, psychological health, and cognitive and developmental outcomes in children living in institutional care, leading international researchers and organisations to advocate for a global policy of deinstitutionalisation.

- In many resource-constrained settings, alternative care options are limited: the adoption and foster care systems remain underdeveloped, while repatriation to a child's extended family may be unsafe or impossible because it is unknown.

- There is a lack of rigorous evidence from lowincome and middle-income countries, and in particular sub-Saharan Africa, about the mental health and well-being of orphaned and separated (those semipermanently or permanently separated from their biological parents) children living in institutional care compared with those in family-based and other care environments such as on the street.

health issues. ${ }^{24-7}$ Africa is home to 52 million single or double orphans. ${ }^{8}$ Although the majority of OSCA are cared for by a surviving parent or extended family, ${ }^{8}$ the large number of children requiring care on the subcontinent led to the proliferation of institutional care (eg, orphanages, rescue centres). Recent research estimates that 650000 to 1.38 million OSCA live in institutional care in sub-Saharan Africa, ${ }^{9}$ building on the previous estimate that 286000 children in eastern and southern Africa were living outside of a family-based setting. ${ }^{10}$

The appropriateness of institutional care for OSCA has been challenged as evidence indicates clear unfavourable short-term and 


\section{Key questions}

\section{What are the new findings?}

- To our knowledge, this is the first prospective cohort to compare mental health outcomes over 10 years among a large sample of orphaned and separated children and adolescents (OSCA) living in three different care environments-institutional care (i.e., orphanages), family-based care (FBC) and self-care on the streets in subSaharan Africa.

- It provides contextually relevant, rigorous evidence about the effect of care environment on OSCA's mental health over time.

- This study found that OSCA in Uasin Gishu County, Kenya, experience a substantial burden of potentially traumatic events in all care environments, and that OSCA living in institutional care were considerably less likely to experience a diagnosis of post-traumatic stress disorder (PTSD), depression, anxiety or suicidality during study follow-up compared with those in FBC, while children and adolescents in self-care on the streets were significantly more likely to be diagnosed with any of the mental health outcomes at any time during study follow-up than those in FBC.

- Our findings indicate that even when examining factors such as social support, basic material possessions, importance of religion and time in nature, which potentially confound the relationship between care environment and mental health, OSCA in institutional care remain significantly less likely to be diagnosed with depression, anxiety and suicidality during study follow-up in comparison to OSCA in FBC.

\section{What do the new findings imply?}

- There is a substantial burden of potentially traumatic events and mental health disorders among OSCA in all care environments examined and community mental health supports for OSCA are urgently needed.

- In order for safe and effective deinstitutionalisation to be implemented at scale, child protection systems need urgently to be strengthened alongside greater investments in evidence-based family supports that improve child and adolescent mental health.

long-term physical and mental health outcomes among many children living in these environments. ${ }^{11}{ }^{12}$ Studies have demonstrated deficits and delays in physical growth, psychological health, and cognitive and developmental outcomes in children living in institutional care. As a result of this evidence, international organisations, backed by influential donors and foundations, have advocated for a global policy of deinstitutionalisation..$^{10} 11$ A large proportion of studies supporting this policy have originated in Eastern Europe, where institutions were particularly socially and emotionally deprived environments, with relatively few from sub-Saharan Africa and other lowincome and middle-income countries (LMICs) ${ }^{11}{ }^{12}$ Traditionally, and still today, extended families care for the overwhelming majority of OSCA in sub-Saharan Africa. Yet, this region has had the highest dependency ratios (the number of children $\leq 15$ years and adults $\geq 65$ per 100 persons of working age) globally for decades and they continue to rise among African households. ${ }^{14} 15$ Sub-Saharan Africa also now has the largest population of people living in extreme poverty, and the World Bank projects that $87 \%$ of the world's poorest are expected to live in sub-Saharan Africa by $2030 .{ }^{16}$ As a result, there is a growing discourse about whether and how institutions might have a 'safety net' role in LMICs when other care options may be unsafe or unavailable. ${ }^{17} 18$ Contextually relevant, rigorous and longitudinal evidence is needed to inform safe and effective deinstitutionalisation policies and interventions, and ensure the best interests of OSCA are being upheld.

Relatively few studies comparatively explore the relationship between care environment and mental health among OSCA in sub-Saharan Africa. ${ }^{49-23}$ These have generally been cross-sectional, qualitative or with relatively small or selective samples, such as only by children orphaned from HIV/AIDS. In general, they provide some indication that children in institutional care may have better, or at least not poorer mental health, than their counterparts in other care environments. Based on this very limited evidence, it remains unclear whether over time OSCA living in institutional care experience more mental health morbidities than those in familybased care, and how OSCA in self-care on the streets, a highly marginalised and largely overlooked population, compare to their counterparts in family-based care $(\mathrm{FBC})$. Further, minimal research to date has examined factors that might mediate or confound the effect between care environment and mental health outcomes for this population, which is critical to identifying targets for intervention development and testing. ${ }^{22}$

This prospective cohort sought to compare the incidence of probable diagnoses of post-traumatic stress disorder (PTSD), depression, anxiety and suicidality between OSCA living in institutional care, streetconnected children and youth (SCY), and those in FBC in one county of western Kenya over almost 10 years, while controlling for known risk and protective factors. Our primary hypothesis was that children living in institutions would have worse mental health over time compared with children in family-based settings. Second, we sought to test whether the relationship between care environment and mental health outcomes remained after adjusting for social support, having basic material possessions, feeling religion is important in one's life, participation in sports and time spent in nature.

\section{METHODS}

\section{Study design and participants}

The Orphaned and Separated Children's Assessments Related to their (OSCAR's) Health and Well-Being Project is a two-phase longitudinal cohort investigating the effects of care environment on the physical and psychosocial well-being of OSCA in Uasin Gishu (UG) County, Kenya. Phase 1 ran from 2010 to 2015 and Phase 2 ran from 2016 to 2019. The study enrolled participants aged 18 years or less from May 2010 to April 2013. The OSCAR cohort comprises participants from communities within eight administrative locations in UG County and includes 300 randomly selected households caring 
for OSCA (FBC), 19 Charitable Children's Institutions (CCIs) (institutional care) (of 21 in the county at the time of study start-up) and a convenience sample of 100 street-connected children and youth (SCY) in 'self-care' on the streets. Children were eligible to participate in the study if they were resident of the care environment at the time, irrespective of orphan status (non-orphaned children were included in order to reduce the risk of stigma against orphans and to provide a small, nested comparator group of non-orphaned children in these same environments), and irrespective of the cause of orphanhood (ie, HIV and all other causes). The present analysis included participants with at least one follow-up visit with a psychosocial assessment. In-depth details about the OSCAR cohort's study design, setting and recruitment have been previously reported. ${ }^{24}$

\section{Human subjects' protections}

This study conforms to the principles embodied in the Declaration of Helsinki. Written informed consent for participation was provided by the head of household, Director of the CCI, or in the case of SCY, by the District (now County) Children's Officer. Individual written informed assent was provided by each child aged 7 years and above. Fingerprints were used for both children and guardians who were unable to sign or write their name.

\section{Patient and public involvement in research}

This study used community-based, participatory processes to inform the research questions, hypotheses and methods, detailed elsewhere. ${ }^{24}$ To summarise briefly, the Children's Officers in the region and representatives from CCIs were initially consulted prior to the funding application. They were requested to provide input as to whether such a study would be important from their perspective, and what their priority questions and concerns were. In addition, traditional community assemblies were held in some of the target communities to identify community concerns and priorities with respect to the care of orphaned and vulnerable children. These assemblies were also held following the initiation of the study to maintain regular contact with the community and disseminate findings. We formed an Advisory Board early on, consisting of representatives from communities, CCIs and Children's Officers, and this board met regularly throughout the life of the study. Our study disseminated findings through the monthly Uasin Gishu Children's Services Forum, through additional traditional community assemblies and through the study website (https://www.oscarcohort.comhttps://www.oscarcohort. com).

\section{Procedures}

Data collection processes were conducted in situ at CCIs and at the OSCAR Project clinic for participants from households and SCY. Annually (semiannually for SCY), participants completed a standardised clinical encounter and those $\geq 10$ years of age also completed a psychosocial encounter. The clinical encounter was an enhanced well-child 'check-up' that included a complete physical history and review of health symptoms. The psychosocial encounter measured education and employment, material well-being, behaviours and risks, peer and family relationships, and mental health. The psychosocial assessment was self-administered for those who could read and write, or psychologist-administered for those that could not adequately read or write. In OSCAR Phase 2, two versions of the psychosocial encounter were employed: one for adolescents aged 10-17 years and one for young adults ( $\geq 18$ years of age) using age-appropriate validated scales and tools to assess PTEs and mental health outcomes. A clinical psychologist was always available during the assessments to assist in case of questions, lack of understanding or distress. Follow-up of cases requiring individual counselling or social work took place on a case-by-case basis as needed, by study staff.

\section{Independent variables}

The primary exposure of interest was care environment (institutional, family-based or street-based), determined by a participant's living circumstances at enrolment. ${ }^{21}$ Separated children were defined as those whose biological mother or father was potentially alive, but functionally not part of the child's life. Sociodemographic characteristics, ascertained through the clinical encounter, included age, sex, orphan/separated status (maternal, paternal, both or neither, in the case of non-orphaned children living in these environments), HIV status (positive, negative, unknown) and time living with caregiver at baseline ( $<6$ months, $6-2$ years, $2-5$ years, $>5$ years, all the child's life). PTEs (physical abuse, sexual abuse, emotional abuse and bullying) were ascertained through the psychosocial encounters. PTEs for those less than 18 years of age were ascertained using the Child Abuse Screening Tool for Children at Home (ICAST-CH) which measures violence against children. ${ }^{25}$ The OSCAR study used 11 questions from ICAST-CH based on extensive consultations with Kenyan psychiatrists, psychologists and paediatricians. There were four questions specific to the emotional domain, three to the physical abuse domain and four questions specific to sexual abuse domain. For all questions, responses took on four levels and included 'Never', 'Sometimes', 'Many times' and 'Not in the past 6 months, but this has happened'. For participants age $\geq 18$, a history of emotional, sexual and physical abuse was assessed using the Childhood Trauma Questionnaire (CTQ) through a five-item subscale: emotional, sexual, and physical abuse, emotional, and physical neglect, as well as three-item subscale to screen for false-negative trauma reports. ${ }^{26-28}$ For all participants, bullying was measured using the eight items from Strengths and Difficulties Questionnaire, ${ }^{29}{ }^{30}$ one item from the Social and Health Assessment Peer Victimisation Scale, ${ }^{31}$ and one question regarding bullying due to orphan status developed by the research team. If participants answered yes to any of these items, a participant was categorised as having 
experienced bullying. For this analysis, we dichotomised (yes /no) the PTE variables to capture any history of physical abuse, sexual abuse, emotional abuse or bullying at baseline and at each follow-up.

Hypothesised factors that may mediate or confound the relationship between care environment and mental health outcomes included: social support (continuous score measured using the 12-item Multidimensional Scale of Perceived Social Support), ${ }^{32} 33$ importance of religion in a participant's life, having basic material possessions (shoes, blanket and at least two pairs of nonschool clothes), ${ }^{34}$ participation in sports and spending time in nature. These factors were measured only on the psychosocial encounter administered to participants 10-17 years of age in OSCAR Phase 2, with the exception of 'importance of religion' that was measured in Phase 1 and Phase 2. They assessed these issues currently and are not able to establish temporality with regard to which came first, care environment, outcome or the third factor. We tested whether there were major differences between these factors and outcomes of interest, and differences between these factors and care environment, and concluded that it would be most appropriate to treat them as potential confounding variables.

\section{Mental health outcomes}

Depression for participants aged 10-17 years was measured with the Child Depression Inventory Short-Form (CDI-SF) with questions specific to the past 2 weeks. ${ }^{35}{ }^{36} \mathrm{In}$ order to approximate a Diagnostic and Statistical Manual (DSM)-IV Test Revision (TR) diagnosis of depression, scores were summed and a cut-off point of 8 was used to determine probable presence of depression in childhood. ${ }^{37}$ Depression for participants $\geq 18$ years of age was measured using the Patient Health Questionnaire (PHQ)-9 (Depression) on a four-point Likert scale. Presence of probable depression in those $\geq 18$ years was diagnosed if a participant scored at least 2 (more than half the day) on two or more of the eight items, of which one had to be either item 1 or 2, consistent with the DSM-IV TR criteria. ${ }^{37-39}$ Adolescent post-traumatic stress was measured using Amaya-Jackson's 'Child PTSD Checklist', a 28-item scale derived from the DSM-IV criteria, which uses a fourpoint Likert severity scale. ${ }^{40}{ }^{41}$ Participants were asked to imagine their worst trauma, and a diagnosis of probable PTSD in adolescents occurred when participants reported currently meeting three diagnostic criteria as indicated by the DSM-IV TR: re-experiencing of the event (a score of 2 or more on any of items $1-5,10,11,14$ ), avoidance symptoms (a score of 2 or more on any three of items 7-9, $12,13,22,25,28$ ) and arousal symptoms (a score of 2 or more on any two of items 15-21). ${ }^{37}$ Post-traumatic stress in young adults was measured using the Post-Traumatic Diagnostic Scale (PDS). A diagnosis of probable PTSD in young adults occurred when participants met the same three diagnostic criteria: re-experiencing of the event (a score of 1 or more on items 1-5), avoidance symptoms (a score of at least 3 or more on items 6-12) and arousal symptoms (a score of at least 2 of items 13-17). ${ }^{42} 43$ Suicidality was measured in adolescents using one question from the CDI-SF scale to ascertain whether they had any suicidal ideation or attempt within the previous 2 weeks. The variable was categorised as no suicidality, suicidal ideation, and suicidal intent, and dichotomised as suicidality (yes/no) in this analysis by combining ideation and intent. Adult suicidality was measured using the PHQ-9 (Suicidality). ${ }^{44-46} \mathrm{~A}$ diagnosis of suicidality for adults occurred when a participant scored 1 or above. Adolescent anxiety was measured using the 28-item Revised Children's Manifest Anxiety Scale (R-CMAS) ${ }^{47}$ Participants were asked about current thoughts and feelings. A cut-off of 19 was used determine presence of probable anxiety based on the participants score on the R-CMAS.

\section{Statistical analysis}

We report mean values and SD or frequencies and percentages for continuous and categorical characteristics, respectively, overall and by care environment. We conducted survival analysis to assess the impact of care environment on four probable diagnostic events: (1) PTSD, (2) depression, (3) anxiety and (4) suicidality. We implemented approaches for recurrent events to account for the fact that individuals may have experienced the events of interest more than once during study follow-up. Time zero was either enrolment into the study or the first visit after the child turned 10 years. For each diagnostic outcome, we present overall survival by care environment using Kaplan-Meier estimates of the cumulative incidence. We use the Prentice-Williams-Peterson (PWP) conditional survival model for recurrent events to evaluate unadjusted and adjusted effects of care environment on each of the four diagnostic outcomes. Adjustment variables were for age, sex, orphan status, length of time in care environment, PTSD/depression/anxiety/ suicidality at baseline, emotional/physical/sexual abuse at baseline and during follow-up, bullied at baseline and during follow-up, and clustering by household/institution. The PWP model is a Cox-extended survival model accounting for clustering due to within-subject correlation and stratifying on the order in which the recurrent events occurred. Robust SEs for the model estimates were calculated to also adjust for clustering by care environment. Results from models are presented as HRs with $95 \%$ CIs. $^{48} 49$

We also conducted a subanalysis, restricted to participants aged 10-18 years in CCIs and FBC (data were not collected on SCY) using data from OSCAR Phase 2 to test whether the relationship between care environment and the outcomes were confounded by social support, basic material possessions, importance of religion and time in nature.

There was no imputation for missing data. All analyses were conducted using RStudio V.1.3.1056.

\section{Role of the funding source}

The funder of the study had no role in study design, data collection, data analysis, data interpretation or writing of 
Table 1 Baseline characteristics

\begin{tabular}{|c|c|c|c|c|}
\hline & Institutional care $(\mathbf{n}=\mathbf{7 8 3})$ & Family based $(\mathrm{n}=1069)$ & Street based $(\mathbf{n}=79)$ & Total $(\mathbf{N}=1931)$ \\
\hline Age (mean $\pm S D)$ & $12.9 \pm 2.23$ & $13 \pm 2.4$ & $15 \pm 2.52$ & $13 \pm 2.37$ \\
\hline \multicolumn{5}{|l|}{ Sex } \\
\hline Female & $354(45.2 \%)$ & $555(51.9 \%)$ & $18(22.8 \%)$ & $927(48.01 \%)$ \\
\hline Male & $429(54.8 \%)$ & $514(48.1 \%)$ & $61(77.2 \%)$ & 1004 (51.99\%) \\
\hline Missing & $0(0 \%)$ & $0(0 \%)$ & $0(0 \%)$ & $0(0 \%)$ \\
\hline \multicolumn{5}{|l|}{ HIV status } \\
\hline HIV negative & $748(95.5 \%)$ & $1051(98.3 \%)$ & $78(98.7 \%)$ & $1877(97.2 \%)$ \\
\hline HIV positive & $35(4.5 \%)$ & $18(1.7 \%)$ & $1(1.3 \%)$ & $54(2.8 \%)$ \\
\hline Missing & $0(0 \%)$ & $0(0 \%)$ & $0(0 \%)$ & $0(0 \%)$ \\
\hline \multicolumn{5}{|l|}{ Orphan status } \\
\hline Double orphan & $646(82.5 \%)$ & $347(32.5 \%)$ & $57(72.2 \%)$ & $1050(54.38 \%)$ \\
\hline Maternal orphan & $45(5.7 \%)$ & $101(9.4 \%)$ & $3(3.8 \%)$ & $149(7.72 \%)$ \\
\hline Paternal orphan & $41(5.2 \%)$ & $460(43 \%)$ & $11(13.9 \%)$ & $512(26.51 \%)$ \\
\hline Non-orphan & $51(6.5 \%)$ & $161(15.1 \%)$ & $8(10.1 \%)$ & $220(11.39 \%)$ \\
\hline Missing & $0(0 \%)$ & $0(0 \%)$ & $0(0 \%)$ & $0(0 \%)$ \\
\hline \multicolumn{5}{|c|}{ Time in care at baseline } \\
\hline$<6$ months & $39(5 \%)$ & $9(0.8 \%)$ & $8(10.1 \%)$ & $56(2.9 \%)$ \\
\hline 6 months-2 years & $101(12.9 \%)$ & $14(1.3 \%)$ & $18(22.8 \%)$ & 133 (6.89\%) \\
\hline $2-5$ years & $261(33.3 \%)$ & $99(9.3 \%)$ & $25(31.6 \%)$ & 385 (19.94\%) \\
\hline$>5$ years & $331(42.3 \%)$ & $148(13.8 \%)$ & $11(13.9 \%)$ & $490(25.38 \%)$ \\
\hline All his/her life & $32(4.1 \%)$ & 793 (74.2\%) & $6(7.6 \%)$ & $831(43.03 \%)$ \\
\hline Missing & $19(2.4 \%)$ & $6(0.6 \%)$ & $11(13.9 \%)$ & $36(1.86 \%)$ \\
\hline
\end{tabular}

Data presented as mean \pm SD or frequencies (\%) for continuous and categorical characteristics, respectively.

the report. The corresponding author had full access to all the data in the study and had final responsibility for the decision to submit for publication.

\section{RESULTS}

\section{Sociodemographic characteristics of participants}

The present analysis included 1931 participants: 1069 in FBC, 783 in CCIs and 79 street-based OSCA (table 1). Overall, $52.0 \%$ of participants were boys and $48.0 \%$ were girls, with a larger proportion of SCY being boys $(77.2 \%)$. The mean age at baseline was 12.9 years (SD 2.4) and 17.6 years (SD 3.4) at follow-up. At baseline, 54 (2.8\%) were HIV-positive, the majority of participants living in institutional care $(82.5 \%)$ and SCY $(72.2 \%)$ were double orphans. The mean follow-up time for participants in institutional care was 59.8 months (SD 31.5), 75.2 months (SD 25.5) in FBC and 73.9 months (SD 31.7) for SCY. A majority of participants $(68.4 \%)$ had been living in that care environment for at least 5 years: $46.4 \%$ of participants in CCIs, $88.0 \%$ of those in FBC and $21.5 \%$ of SCY. Nearly $32 \%$ of SCY were on the street for $2-5$ years.

\section{Mental health outcomes and PTEs}

Mental health outcomes and PTEs differed between care environments at baseline and last follow-up visit (table 2). Participants living in institutional care were less frequently diagnosed with probable suicidality $(12.8 \%)$, PTSD (11.1\%), depression (5.7\%) and anxiety $(4.2 \%)$ than those in FBC $(21.3 \% ; 16.0 \% ; 20.3 \% ; 8.8 \%)$ at baseline. SCY were more frequently diagnosed with all mental health outcomes at baseline than participants in other care environments. At last follow-up visit, OSCA in CCIs were less frequently diagnosed with PTSD $(13.8 \%)$ and depression $(11.0 \%)$ than those in FBC $(18.3 \%$ and $15.1 \%)$. Fewer participants in FBC reported suicidality (11.7\%) compared with those in CCIs (14.2\%). SCY were more frequently diagnosed with probable depression $(15.2 \%)$ and anxiety $(13.9 \%)$ and less frequently diagnosed with probable PTSD $(7.6 \%)$ and suicidality $(11.4 \%)$ at last follow-up than those in FBC and CCIs.

PTEs were highly prevalent. Fewer participants in FBC $(72.7 \%)$ reported bullying at baseline than those in CCIs (81.7\%). OSCA in CCIs less frequently reported sexual abuse $(13.2 \%)$ at baseline compared with those in FBC (18.7\%). At last follow-up, fewer participants in CCIs reported any physical $(48.8 \%)$, emotional $(46.1 \%)$ or sexual abuse $(20.9 \%)$ compared with those in FBC $(57.3 \% ; 51.9 \% ; 34.7 \%)$. SCY had a higher prevalence of all PTEs at baseline and last follow-up visit compared with those in CCIs and FBC.

In a subanalysis for which data were available, participants living in CCIs more frequently reported that 


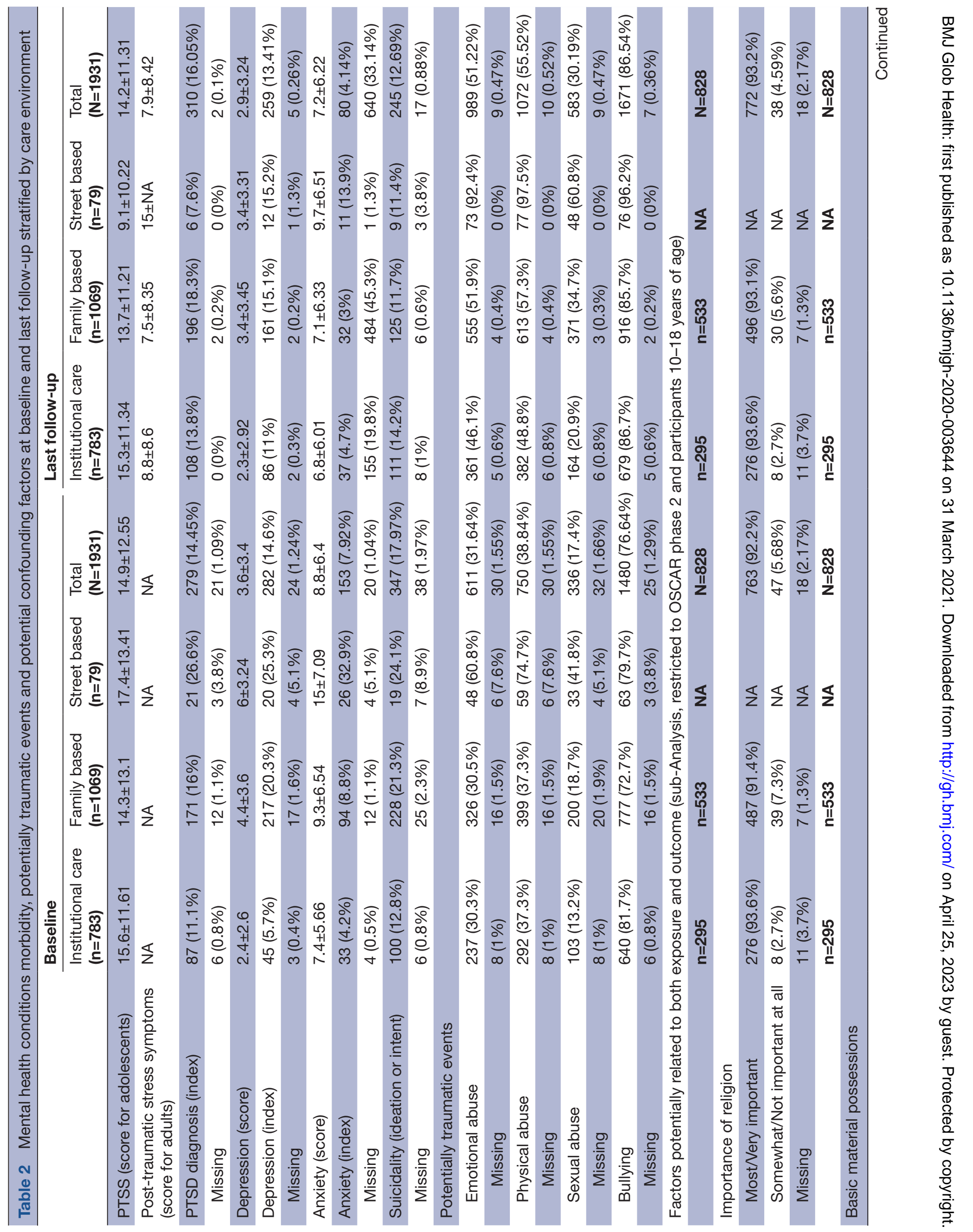




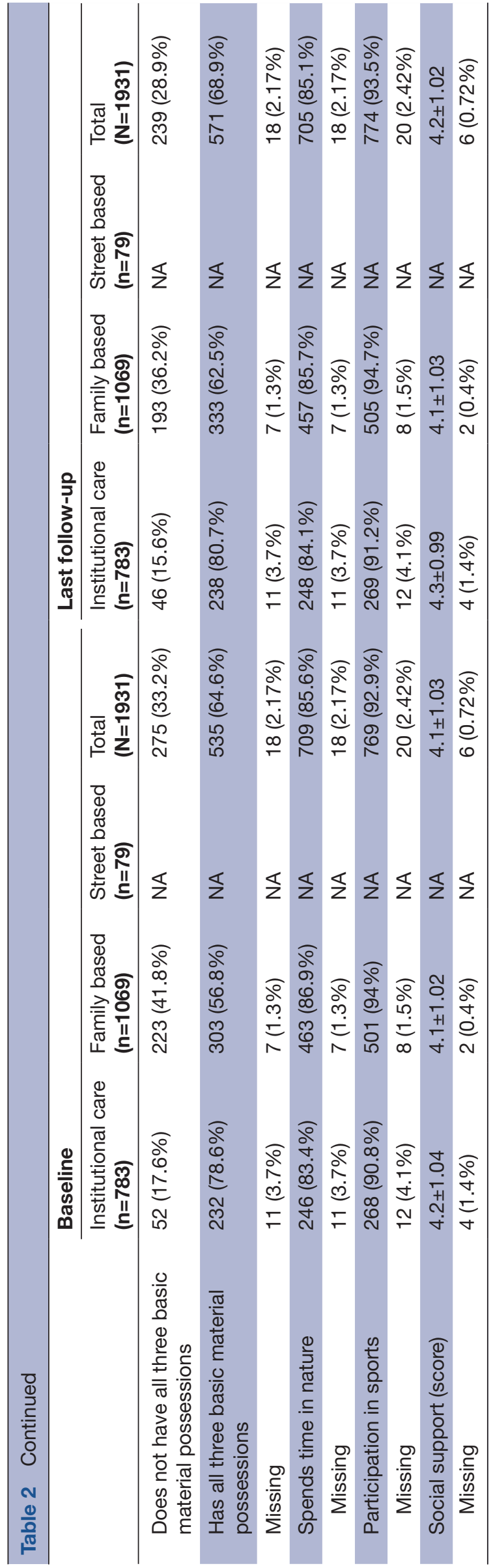

religion was most or very important in their everyday lives than those in FBC. A higher percentage of OSCA in CCIs had all three basic material possessions at baseline $(78.6 \%)$ and follow-up $(80.7 \%)$ compared with those in FBC, $56.8 \%$ and $62.5 \%$, respectively. Social support scores were similar across care environments, with a mean score of 4.2 (SD 1.02) at last follow-up, indicative of moderate social support.

\section{Survival analysis}

There were 3382 mental health events reported in 133083 person-months of follow-up: 46809 in CCIs, 80440 in FBC and 5835 in SCY. Participants in institutional care had a longer median time to probable PTSD diagnosis (98.6 months, $95 \%$ CI 97.8 to 103.9) than those in FBC (91.9 months, 95\% CI 89.9 to 94.5 ) and SCY (36.70 months, 95\% CI 34.5 to NA) (figure 1). Likewise, participants in CCIs had a longer median time to probable suicidality (98.4 months, $95 \%$ CI 97.8 to NA) in comparison to those in FBC (94.5 months, 95\% CI 92.2 to 97.4 ) and SCY (34.5 months $95 \%$ CI 25.7 to NA) (figure 1). Participants in FBC (91.7 months (95\% CI 87.6-94.3) had a longer median depression survival time than SCY (34.5 (95\% CI 27.5 to NA). Fewer than $50 \%$ of participants in institutional and FBC experienced a diagnosis of anxiety, while SCY had a median time to diagnosis of probable anxiety of 30.5 months (95\% CI 24.2 to NA) (figure 1).

In adjusted models (unadjusted analyses in online supplemental table 1), OSCA in CCIs were significantly less likely to be diagnosed with probable PTSD (AHR $0.69,95 \%$ CI 0.49 to 0.97 ), depression (AHR $0.48,95 \%$ CI 0.24 to 0.97 ), anxiety (AHR $0.56,95 \%$ CI 0.45 to 0.68 ) and suicidality (AHR $0.73,95 \%$ CI 0.56 to 0.95 ) during study follow-up compared with those in FBC while adjusting for age, sex, orphan status, time living in care environment, PTEs at baseline and follow-up, mental health diagnoses at baseline and clustering by household/institution (table 3). SCY were significantly more likely to be diagnosed with PTSD (AHR 4.52, 95\% CI 4.10 to 4.97), depression (AHR 4.72, 95\% CI 3.12 to 7.15), anxiety (AHR 4.71, 95\% CI 1.56 to 14.26), and suicidality (AHR 3.10, 95\% CI 2.14 to 4.48) compared with those in FBC while adjusting for these same variables.

In adjusted subanalyses (unadjusted analyses in online supplemental table 2), OSCA in CCIs remained significantly less likely to be diagnosed with depression, anxiety and suicidality during follow-up, when examining the potentially confounding effects of social support, basic material possessions, importance of religion and time in nature (table 4). When adjusting for each of the five factors separately, that is, all three basic material possessions, considering religion most or very important in everyday life, and spending time in nature, the association of care environment on the diagnosis of probable PTSD became non-significant. Social support and importance of religion were consistently protective (in addition to care environment) against all outcomes, while having 
Post-Traumatic Stress Disorder (PTSD) syndrome

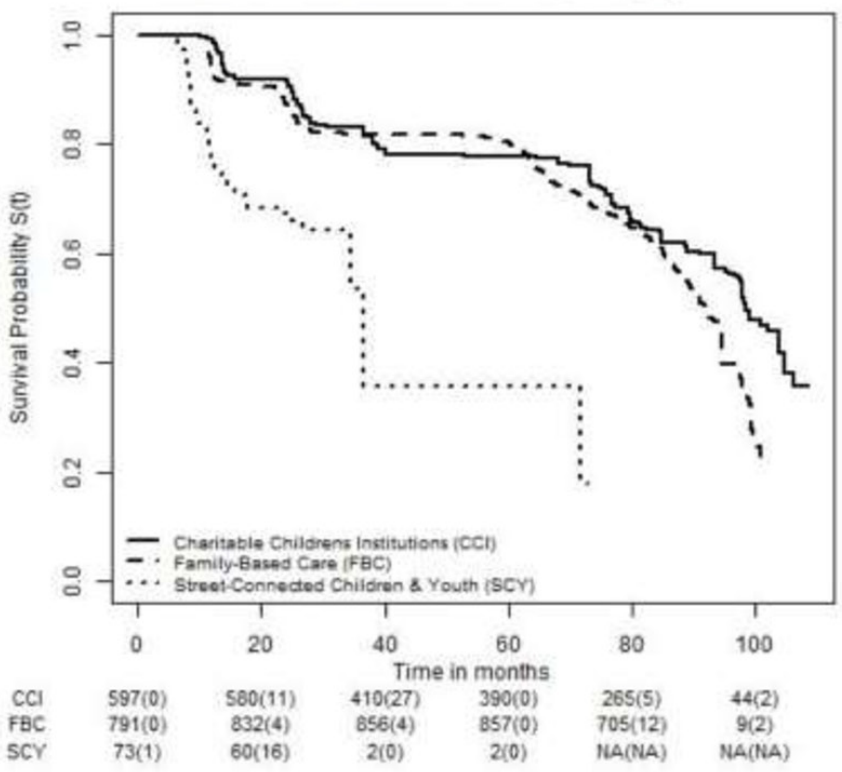

Anxiety

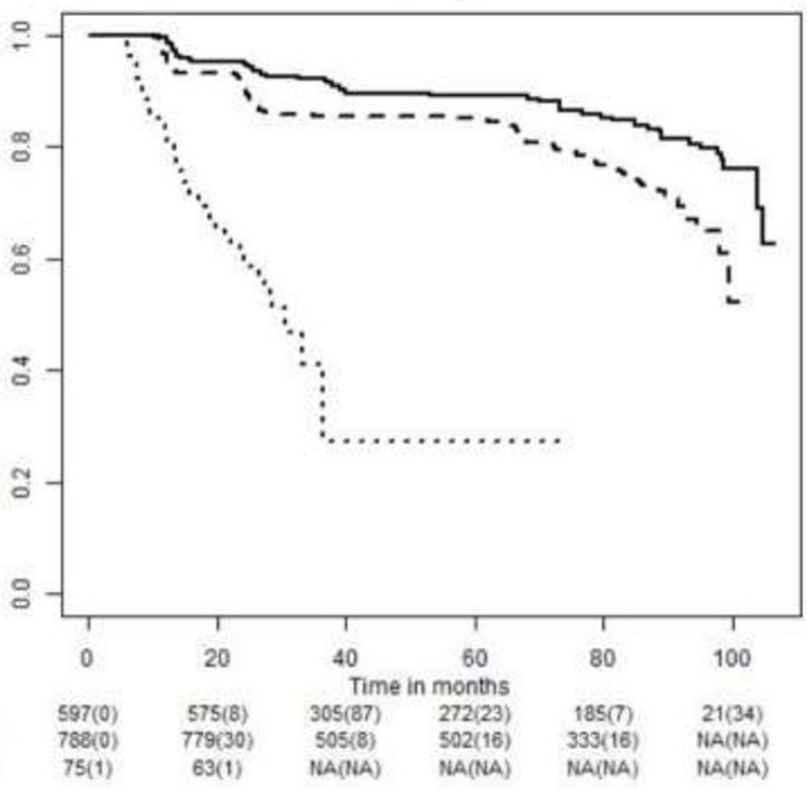

Depression
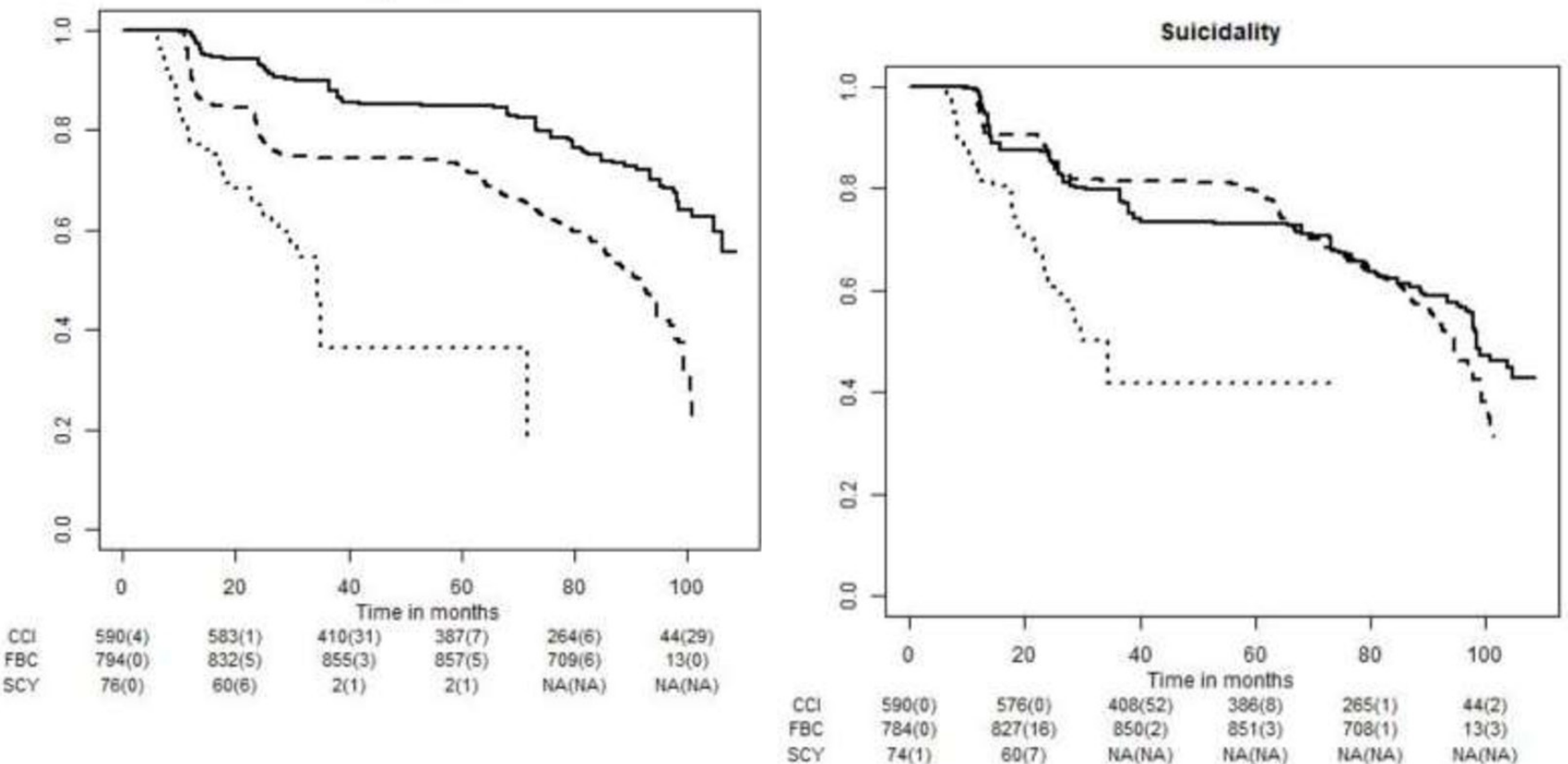

Figure 1 Kaplan-Meier survival curves of time to a new mental health diagnosis. CCl, Charitable Children's Institution; FBC, family-based care; SCY, street-connected children and youth.

Table 3 Adjusted HRs and $95 \%$ Cls of the effect of care environment on mental health diagnoses

\begin{tabular}{lllll}
\hline Care environment & PTSD & Depression & Anxiety & Suicidality \\
\hline Family based (ref) & 1 & 1 & 1 & 1 \\
Institutional care & $0.69(0.49,0.97)$ & $0.48(0.24,0.97)$ & $0.56(0.45,0.68)$ & $0.73(0.56,0.95)$ \\
Street based & $4.52(4.1,4.97)$ & $4.72(3.12,7.15)$ & $4.71(1.56,14.26)$ & $3.1(2.14,4.48)$
\end{tabular}

HRs adjusted for age, sex, orphan status, length of time in care environment, PTSD/depression/anxiety/suicidality at baseline, emotional/ physical/sexual abuse at baseline and during follow-up, bullied at baseline and during follow-up, clustering by household/institution. PTSD, post-traumatic stress disorder; (ref), reference category. 
Table 4 Adjusted HRs and 95\% Cls examining impact of additional potential confounders of the relationship between care environment and mental health diagnoses

Factors potentially associated with both exposure and outcome (potential confounders)

\begin{tabular}{|c|c|c|c|c|c|}
\hline & Overall & Social support & $\begin{array}{l}\text { Basic material } \\
\text { possessions }\end{array}$ & $\begin{array}{l}\text { Importance of } \\
\text { religion }\end{array}$ & Time in nature \\
\hline & PTSD & & & & \\
\hline Care environment (FBC (ref)) & 1 & 1 & 1 & 1 & 1 \\
\hline Institution & $0.57(0.48-0.68)$ & $0.60(0.51-0.71)$ & $0.66(0.36-1.21)$ & $0.62(0.37-1.05)$ & $0.60(0.36-1.02)$ \\
\hline Social support & & $0.73(0.72-0.73)$ & & & \\
\hline All 3 basic material possessions & & & $0.72(0.45-1.13)$ & & \\
\hline Importance of religion (Most/Very) & & & & $0.72(0.59-0.88)$ & \\
\hline \multirow[t]{2}{*}{ Spends time in nature } & & & & & $0.86(0.42-1.78)$ \\
\hline & Depression & & & & \\
\hline Care environment (FBC (ref)) & 1 & 1 & 1 & 1 & 1 \\
\hline Institution & $0.29(0.13-0.64)$ & $0.30(0.15-0.61)$ & $0.33(0.11-0.94)$ & $0.28(0.08-0.97)$ & $0.25(0.08-0.78)$ \\
\hline Social support & & $0.67(0.48-0.94)$ & & & \\
\hline All 3 basic material possessions & & & $0.57(0.49-0.66)$ & & \\
\hline Importance of religion (Most/Very) & & & & $0.47(0.47-0.48)$ & \\
\hline \multirow[t]{2}{*}{ Spends time in nature } & & & & & $0.78(0.26-2.30)$ \\
\hline & Anxiety & & & & \\
\hline Care environment (FBC (ref)) & 1 & 1 & 1 & 1 & 1 \\
\hline Institution & $0.69(0.68-0.70)$ & $0.69(0.66-0.71)$ & $0.75(0.68-0.82)$ & $0.72(0.70-0.75)$ & $0.70(0.67-0.73)$ \\
\hline Social support & & $0.83(0.57-1.23)$ & & & \\
\hline All 3 basic material possessions & & & $0.70(0.40-1.24)$ & & \\
\hline Importance of religion (Most/Very) & & & & $0.43(0.37-0.51)$ & \\
\hline \multirow[t]{2}{*}{ Spends time in nature } & & & & & $0.89(0.64-1.25)$ \\
\hline & Suicidality & & & & \\
\hline Care environment (FBC (ref)) & & 1 & 1 & 1 & 1 \\
\hline Institution & $0.52(0.39-0.70)$ & $0.57(0.47-0.68)$ & $0.61(0.43-0.86)$ & $0.50(0.35-0.72)$ & $0.49(0.36-0.66)$ \\
\hline Social support & & $0.73(0.71-0.74)$ & & & \\
\hline All 3 basic material possessions & & & $0.44(0.36-0.55)$ & & \\
\hline Importance of religion (Most/Very) & & & & $0.51(0.44-0.58)$ & \\
\hline Spends time in nature & & & & & $0.88(0.57-1.36)$ \\
\hline
\end{tabular}

Adjusted for age, sex, orphan status, length of time in care environment, PTSD/depression/anxiety/suicidality at baseline, emotional/ physical/sexual abuse at baseline and during follow-up, bullied at baseline and during follow-up, clustering by household/institution. FBC, family-based care; PTSD, post-traumatic stress disorder.

basic material possessions was positively associated with depression and suicidality, but neither PTSD nor anxiety.

\section{DISCUSSION}

This study comparing mental health outcomes of OSCA living in three different care environments in UG County Kenya has four principal findings. First, we found a significant burden of PTEs across all participants in all care environments and a high probability of being diagnosed with mental health illnesses over time. Second, OSCA living in institutional care were significantly less likely to be diagnosed with probable PTSD, depression, anxiety or suicidality than those in FBC over the course of the study after controlling for confounding and other relevant factors. Third, SCY's risk of being diagnosed with a mental health illness during the study was significantly higher than OSCA in either of the other two care environments. Fourth, social support and importance of religion were found to be consistently associated with better outcomes, while having basic material possessions reduced the risk of depression and suicidality.

This study adds to the body of research from subSaharan Africa that has demonstrated that children who have lost one or both parents experience multiple PTEs ${ }^{2-4}$ and have substantial mental health issues. ${ }^{24-7}$ Bullying, physical, emotional and sexual abuse are highly prevalent 
in sub-Saharan Africa. ${ }^{50} 51$ The significant burden of PTEs across all participants at baseline and during study follow-up is noteworthy, given the well-established association between experiencing multiple adverse childhood experiences and the risk of developing mental illnesses. ${ }^{1}$ Evidence demonstrates that $10 \%-20 \%$ of children and adolescents living in LMICs experience mental health problems. ${ }^{52}$ The present study found the prevalence of mental health morbidities among OSCA living in institutional and FBC was within this range at baseline and follow-up. However, the prevalence of SCY's mental health morbidities well exceeded it.

Contrary to findings from other settings such as Eastern Europe, ${ }^{11} 1253$ our results do not support the hypothesis that OSCA living in institutional care have worse mental health outcomes over time than those in FBC, and add to the mounting evidence that children in institutional care in sub-Saharan Africa may have better mental health than their counterparts in other care environments. ${ }^{4} 192223$ Furthermore, our findings confirm that OSCA living and working on the streets have poorer mental health outcomes than those living in the other care environments examined. ${ }^{4}{ }^{19}$ SCY's higher risk of mental health problems is likely a result of the very high prevalence of PTEs experienced once on the street, ${ }^{4} 54$ and the adversities at home that prompted them to migrate to the street. ${ }^{55}$

After adjusting for potentially confounding factors, OSCA living in institutional care remained significantly less likely to experience a diagnosis of probable depression, anxiety or suicidality during follow-up than those in FBC. Importantly, social support and considering religion most/very important were consistently protective against all outcomes, which supports the concept that the quality of care and other factors may have a stronger effect on OSCA's psychosocial health than the care environment itself. ${ }^{56}$

The mental health of children in LMICs has been relatively neglected, ${ }^{57}$ and interventions to address child and adolescent mental health in LMICs are scarce. ${ }^{52} 58$ Given the prevalence of and differences in mental health outcomes by care environment this study has found, no 'one size fits all' approach will work to address these issues. For deinstitutionalisation to occur safely, effectively and at scale, a diverse range of evidence-based, targeted interventions are urgently needed, including a responsive child protection system, substantially more investments in family supports, and a health system that is resourced and able to respond to OSCA's significant mental health needs irrespective of their care environment.

This study has several important strengths. First, it was able to longitudinally screen a relatively large number of OSCA orphaned from all causes for mental health problems and PTEs across different care environments, increasing generalisability. Second, we were able to include SCY in this study to represent self-care, and although the number of SCY in our sample was relatively small, these findings to our knowledge provide the first longitudinal estimates on SCY's mental health in sub-Saharan Africa. Finally, this study provides rigorous and contextually relevant evidence to inform policy on optimal care environments and deinstitutionalisation for OSCA in sub-Saharan Africa and shows that OSCA living in family-based settings clearly need more support and attention before rapid, universal implementation of deinstitutionalisation can be successfully accomplished.

This study also has limitations. First, the study instruments measuring PTSD, depression, suicidality and anxiety across adolescents and young adults were not validated in this study population, and therefore may not accurately reflect the symptoms and diagnoses of these outcomes in OSCA in this context. Second, measures of mental health outcomes, PTEs and other potential confounding factors were self-reported and could be prone to reporting bias; however, this bias is likely nondifferential, as irrespective of care environment, participants may have been afraid to disclose PTEs or mental health problems for fear of repercussions from their caregiver(s). Third, we use statistical methods for recurrent events, assuming that each identified event corresponds to a 'new' event. Finally, these findings may not be generalisable to other counties in Kenya due to differences across the country.

\section{CONCLUSION}

Overall, our findings demonstrate that OSCA in this region urgently require targeted mental health interventions to address multiple morbidities across all care environments. These morbidities may have life-long consequences on the overall health and well-being of these vulnerable populations if left unaddressed. Deinstitutionalisation may be most effective, sustainable and scalable if implemented when and if the appropriate family and government supports are in place at a national and subnational level.

\section{Author affiliations}

${ }^{1}$ Mental Health, Moi Teaching and Referral Hospital, Eldoret, Kenya

${ }^{2}$ Biostatistics, Brown University School of Public Health, Providence, Rhode Island, USA

${ }^{3}$ Epidemiology, University of Toronto Dalla Lana School of Public Health, Toronto Ontario, Canada

${ }^{4}$ Mental Health, Moi University College of Health Sciences, Eldoret, Kenya ${ }^{5}$ Behavioral Sciences, Moi University College of Health Sciences, Eldoret, Kenya ${ }^{6}$ Data Management and Biostatistics, Academic Model Providing Access to Healthcare, Eldoret, Kenya

Acknowledgements We wish to gratefully acknowledge the Chiefs, Assistant Chiefs and Village Elders of the Locations of Pioneer, Kapsoya, Koisagat, Ol'Lenguse, Olare, Tarakwa, Kipsinende and Kapyemit for their support and leadership. We also wish to acknowledge all the residents of these locations and particularly the many households caring for vulnerable members of their community, notably orphaned and separated children, children with physical and mental disabilities, and the elderly. We particularly want to acknowledge the County and District Children's Officers, particularly Mr Philip Nzenge, for their dedication to protecting the children of Uasin Gishu County, as well as the Uasin Gishu Children's Services Forum. This study would not have been possible without the willing participation of the children and youth participants and their guardians and we would like to acknowledge and thank them. The enthusiasm and commitment of 
the staff and volunteers of the OSCAR project have not gone unnoticed and we the authors wish to thank them for their efforts and engagement with this project.

Contributors FO and LEE drafted the manuscript. SC conducted the analysis. DOA and LA guided study hypotheses, data collection, interpretation of results and reviewed manuscript drafts. ES assisted with data collection, construction of the analysis data and revised the draft manuscript. PB conceived the idea for this study, guided all aspects of study design, data collection, analysis and interpretation of the findings. All authors reviewed and approved the final manuscript for submission.

Funding This project was supported by the Eunice Kennedy Shriver National Institute of Child Health \& Human Development (R01HD060478). The content is solely the responsibility of the authors and does not necessarily represent the official views of the Eunice Kennedy Shriver National Institute of Child Health \& Human Development or the National Institutes of Health.

Competing interests None declared.

Patient consent for publication Not required

Ethics approval The Moi University College of Health Sciences and MTRH Institutional Research and Ethics Committee, the Indiana University Institutional Review Board, and the University of Toronto Research Ethics Boards approved this study.

Provenance and peer review Not commissioned; externally peer reviewed.

Data availability statement Data are available upon request. The deidentified analysis dataset is available to other researchers and others upon request by emailing the corresponding author.

Supplemental material This content has been supplied by the author(s). It has not been vetted by BMJ Publishing Group Limited (BMJ) and may not have been peer-reviewed. Any opinions or recommendations discussed are solely those of the author(s) and are not endorsed by BMJ. BMJ disclaims all liability and responsibility arising from any reliance placed on the content. Where the content includes any translated material, BMJ does not warrant the accuracy and reliability of the translations (including but not limited to local regulations, clinical guidelines, terminology, drug names and drug dosages), and is not responsible for any error and/or omissions arising from translation and adaptation or otherwise.

Open access This is an open access article distributed in accordance with the Creative Commons Attribution Non Commercial (CC BY-NC 4.0) license, which permits others to distribute, remix, adapt, build upon this work non-commercially, and license their derivative works on different terms, provided the original work is properly cited, appropriate credit is given, any changes made indicated, and the use is non-commercial. See: http://creativecommons.org/licenses/by-nc/4.0/.

ORCID iD

Paula Braitstein http://orcid.org/0000-0003-0541-2955

\section{REFERENCES}

1 Hughes K, Bellis MA, Hardcastle KA, et al. The effect of multiple adverse childhood experiences on health: a systematic review and meta-analysis. Lancet Public Health 2017;2:e356-66.

2 Whetten K, Ostermann J, Whetten R, et al. More than the loss of a parent: potentially traumatic events among orphaned and abandoned children. J Trauma Stress 2011;24:174-82.

3 Gray CL, Pence BW, Ostermann J, et al. Prevalence and incidence of traumatic experiences among orphans in institutional and familybased settings in 5 low- and middle-income countries: a longitudina study. Glob Health Sci Pract 2015;3:395-404.

4 Atwoli L, Ayuku D, Hogan J, Koech J, et al. Impact of domestic care environment on trauma and posttraumatic stress disorder among orphans in Western Kenya. PLoS One 2014;9:e89937.

5 Atwine B, Cantor-Graae E, Bajunirwe F. Psychological distress among AIDS orphans in rural Uganda. Soc Sci Med 2005;61:555-64.

6 Cluver LD, Orkin M, Gardner F, et al. Persisting mental health problems among AIDS-orphaned children in South Africa. J Child Psychol Psychiatry 2012;53:363-70.

7 Nduwimana E, Mukunzi S, Ng LC, et al. Mental health of children living in foster families in rural Rwanda: the role of HIV and the family environment. AIDS Behav 2017;21:1518-29.

8 UNICEF. Orphans, 2015. Available: https://www.unicef.org/media/ orphans

9 Desmond C, Watt K, Saha A, et al. Prevalence and number of children living in institutional care: global, regional, and country estimates. Lancet Child Adolesc Health 2020;4:370-7.
10 Petrowski N, Cappa C, Gross P. Estimating the number of children in formal alternative care: challenges and results. Child Abuse Negl 2017;70:388-98.

11 Berens AE, Nelson CA. The science of early adversity: is there a role for large institutions in the care of vulnerable children? Lancet 2015;386:388-98.

12 van IJzendoorn MH, Bakermans-Kranenburg MJ, Duschinsky R, et al. Institutionalisation and deinstitutionalisation of children 1: a systematic and integrative review of evidence regarding effects on development. Lancet Psychiatry 2020;7:703-20.

13 Boyce N, Godsland J, Sonuga-Barke E. Institutionalisation and deinstitutionalisation of children: the executive summary from a Lancet group Commission. Lancet Child Adolesc Health 2020;4:562-3.

14 Harwood RH, Sayer AA, Hirschfeld M. Current and future worldwide prevalence of dependency, its relationship to total population, and dependency ratios. Bull World Health Organ 2004;82:251-8.

15 edUNCTAD. Fact sheet \#12: age structure. In: UNCTAD handbook of statistics 2017 - population. Geneva: UNCTAD, 2017. https://unctad. org/en/PublicationChapters/tdstat42_FS12_en.pdf

16 Roser M, Ortiz-Ospina E. Global extreme PovertyR. Washington, DC: World Bank, 2019. https://ourworldindata.org/extreme-poverty\#: : text=As\%20we\%20can\%20see\%2C\%20globally,million\%20every\% 20year\%20since\%201990

17 Braitstein P. Institutional care of children in low- and middle-income settings: challenging the conventional wisdom of Oliver twist. Glob Health Sci Pract 2015:3:330-2.

18 Huynh HV. New directions in orphan and vulnerable children policy and research: A focus on supporting "suitable" institutions when placement is "necessary" for a child. Am J Orthopsychiatry 2014;84:387-94

19 Caserta TA, Pirttilä-Backman A-M, Punamäki R-L. The association between psychosocial well-being and living environments: a case of orphans in Rwanda. Child Fam Soc Work 2017;22:881-91.

20 Whetten K, Ostermann J, Pence BW, et al. Three-Year change in the wellbeing of orphaned and separated children in institutional and family-based care settings in five low- and middle-income countries. PLoS One 2014:9:e104872.

21 Whetten K, Ostermann J, Whetten RA, et al. A comparison of the wellbeing of orphans and abandoned children ages 6-12 in institutional and community-based care settings in 5 less wealthy nations. PLoS One 2009;4:e8169.

22 Barenbaum E, Smith T. Social support as a protective factor for children impacted by HIV/AIDS across varying living environments in southern Africa. AIDS Care 2016;28 Suppl 2:92-9.

23 Schaal S, Elbert T. Ten years after the genocide: trauma confrontation and posttraumatic stress in Rwandan adolescents. $J$ Trauma Stress 2006;19:95-105.

24 Kamanda A, Embleton L, Ayuku D, et al. Harnessing the power of the grassroots to conduct public health research in sub-Saharan Africa: a case study from Western Kenya in the adaptation of community-based participatory research (CBPR) approaches. BMC Public Health 2013;13:91.

25 Mbassa Menick D, Runyan D, In: ICQ. ICAST child Questonnaire. In: (UNICEF) ISftPoAaNIUNCsF, ed. Chapel Hill: University of North Carolina, 2006.

26 Bernstein D, Fink L, Handelsman L. Childhood trauma questionnaire. APA PsychTests, 1994

27 Bernstein DP, Fink L. Childhood trauma questionnaire: a retrospective self-report. manual. New York: Psychological Corporation, 1998.

28 Liebschutz JM, Buchanan-Howland K, Chen CA, et al. Childhood trauma questionnaire (CTQ) correlations with prospective violence assessment in a longitudinal cohort. Psychol Assess 2018;30:841-5.

29 Goodman R. The strengths and difficulties questionnaire: a research note. J Child Psychol Psychiatry 1997;38:581-6.

30 Vostanis P. Strengths and difficulties questionnaire: research and clinical applications. Curr Opin Psychiatry 2006;19:367-72.

31 Joseph S, Stockton $\mathrm{H}$. The multidimensional peer victimization scale: a systematic review. Aggress Violent Behav 2018;42:96-114.

32 Bruwer B, Emsley R, Kidd M, et al. Psychometric properties of the multidimensional scale of perceived social support in youth. Compr Psychiatry 2008;49:195-201.

33 Zimet GD, Dahlem NW, Zimet SG, et al. The multidimensional scale of perceived social support. J Pers Assess 1988;52:30-41.

34 UNICEF. Children in especially difficult circumstances. New York: UNICEF, 1986

35 Ahlen J, Ghaderi A. Evaluation of the children's depression Inventory-short version (CDI-S). Psychol Assess 2017;29:1157-66. 
36 Traube D, Dukay V, Kaaya S, et al. Cross-Cultural adaptation of the child depression inventory for use in Tanzania with children affected by HIV. Vulnerable Child Youth Stud 2010;5:174-87.

37 American Psychiatric Association. Diagnostic and statistical manual of mental disorders DSM-5. Fifth Edition. Washington, D.C.: American Psychiatric Association, 2013.

38 Monahan $\mathrm{PO}$, Shacham $\mathrm{E}$, Reece $\mathrm{M}$, et al. Validity/reliability of $\mathrm{PHQ}$ 9 and PHQ-2 depression scales among adults living with HIV/AIDS in Western Kenya. J Gen Intern Med 2009;24:189-97.

39 Omoro SAO, Fann JR, Weymuller EA, et al. Swahili translation and validation of the patient health Questionnaire- 9 depression scale in the Kenyan head and neck cancer patient population. Int $J$ Psychiatry Med 2006;36:367-81.

40 Boyes ME, Cluver LD, Gardner F. Psychometric properties of the child PTSD checklist in a community sample of South African children and adolescents. PLoS One 2012;7:e46905.

41 Kohrt BA, Jordans MJD, Tol WA, et al. Validation of cross-cultural child mental health and psychosocial research instruments: adapting the depression self-rating scale and child PTSD symptom scale in Nepal. BMC Psychiatry 2011;11:127.

42 Foa EB. Post-Traumatic diagnostic scale (PDS-5. Washington, DC: U.S. Department of Veterans Affairs, 2013. https://www.ptsd.va.gov/ professional/assessment/adult-sr/pds.asp\#: :text=Posttraumatic\% 20Diagnostic\%20Scale\%20(PDS\%2D5)\&text=The\%20PDS\%2D5\% 20is\%20a,and\%20identify\%20an\%20index\%20trauma

43 McCarthy S. Post-Traumatic stress diagnostic scale (PDS). Occup Med 2008;58:379

44 Adewuya AO, Ola BA, Afolabi OO. Validity of the patient health questionnaire (PHQ-9) as a screening tool for depression amongst Nigerian university students. J Affect Disord 2006;96:89-93.

45 Martin A, Rief W, Klaiberg A, Braehler E, et al. Validity of the brief patient health questionnaire mood scale (PHQ-9) in the general population. Gen Hosp Psychiatry 2006;28:71-7.

46 Kroenke K, Spitzer RL, Williams JBW. The PHQ-9. J Gen Intern Med 2001;16:606-13.

47 Gerard A, Reynolds C. Characteristics and applications of the Revised Children's Manifest Anxiety Scale, in The use of psychological testing for treatment and planning and outcomes assessment. Second ed. Mahwah: Lawrence Erlbaum, 1999.

48 Prentice RL, Williams BJ, Peterson AV. On the regression analysis of multivariate failure time data. Biometrika 1981;68:373-9.

49 Therneau TM, Grambsch PM. Modeling survival data: extending the COX model. New York: Springer-Verlag, 2000: 2053-4.

50 Hillis S, Mercy J, Amobi A, et al. Global prevalence of Past-year violence against children: a systematic review and minimum estimates. Pediatrics 2016;137:e20154079.

51 Brown DW, Riley L, Butchart A, et al. Bullying among youth from eight African countries and associations with adverse health behaviors. Ped Health 2008;2:289-99.

52 Kieling $\mathrm{C}$, Baker-Henningham $\mathrm{H}$, Belfer $\mathrm{M}$, et al. Child and adolescent mental health worldwide: evidence for action. Lancet 2011;378:1515-25.

53 Ahmad A, Qahar J, Siddiq A, et al. A 2-year follow-up of orphans' competence, socioemotional problems and post-traumatic stress symptoms in traditional foster care and orphanages in Iraqi Kurdistan. Child Care Health Dev 2005;31:203-15.

54 Seidel S, Chang J, Mwongera GM, et al. Vulnerability of streetinvolved children and youth in semi-rural Kenya: does orphan status matter? Vulnerable Child Youth Stud 2017;12:207-14

55 Embleton L, Lee H, Gunn J, et al. Causes of child and youth homelessness in developed and developing countries: a systematic review and meta-analysis. JAMA Pediatr 2016;170:435-44.

56 Huynh HV, Limber SP, Gray CL, et al. Factors affecting the psychosocial well-being of orphan and separated children in five low- and middle-income countries: which is more important, quality of care or care setting? PLoS One 2019;14:e0218100.

57 Lu C, Li Z, Patel V. Global child and adolescent mental health: the orphan of development assistance for health. PLoS Med 2018;15:e1002524.

58 Morris J, Belfer M, Daniels A, et al. Treated prevalence of and mental health services received by children and adolescents in 42 low-and-middle-income countries. J Child Psychol Psychiatry 2011:52:1239-46. 